\title{
A narrative review of vitamin D and food allergy in infants and children
}

\author{
Tianwei Di, Lihua Chen
}

Neonatology Department, The Children's Hospital of Zhejiang University School of Medicine, Hangzhou, China

Contributions: (I) Conception and design: T Di; (II) Administrative support: L Chen; (III) Provision of study materials or patients: T Di; (IV) Collection and assembly of data: T Di; (V) Data analysis and interpretation: T Di; (VI) Manuscript writing: Both authors; (VII) Final approval of manuscript: Both authors.

Correspondence to: Lihua Chen. Neonatology Department, The Children's Hospital of Zhejiang University School of Medicine, 3333 Binsheng Road, Hangzhou 310052, China. Email: chebq@zju.edu.cn.

Objective: This article summarizes the research progress on the association of vitamin D and food allergy in infants and children.

Background: In recent years, food allergy seriously has affected the quality of life of children and adults. Vitamin D is known to be involved in calcium and phosphorus metabolism, and recent research has demonstrated that vitamin D can also affect the immune regulation of food allergy.

Methods: The present study summarizes the research progress on the association of vitamin D and food allergy in infants and children. We searched the PubMed database to identify studies on the association of vitamin D and food allergy published between January 2003 and August 2021.

Conclusions: Vitamin D in the body through a number of steps into the final formation of biological effects. The implications of postnatal vitamin D levels for food allergy may be even greater. Vitamin D can prevent the intestinal immune system from being exposed to allergens by maintaining the integrity of the mucosal barrier. Many clinical studies believe that vitamin D supplementation can improve infants' and children's food allergy, however, some show negative results or opposite results. A lot of laboratory studies have confirmed that vitamin $\mathrm{D}$ is involved in the immune regulation of food allergy. Evidence indicates there may be a nonlinear relationship between vitamin D and food allergy. Further researches need to be launched.

Keywords: Vitamin D; food allergy; infant and children

Submitted Jul 08, 2021. Accepted for publication Sep 24, 2021.

doi: $10.21037 / \mathrm{tp}-21-396$

View this article at: https://dx.doi.org/10.21037/tp-21-396

\section{Introduction}

In 1928, Adolf Windaus was awarded the Nobel Prize in Chemistry for his outstanding contributions to vitamin D research. At the end of the 20th century, vitamin D once again became a research hotspot due to its potential benefits other than bone metabolism.

Allergic disease involves immune dysfunction. In recent years, the incidence of food allergy in China has been gradually increasing, which seriously affects the quality life of people, especially for infants and children. Many previously published studies have demonstrated that vitamin
D has immunomodulatory effects on food allergy; however, others disagree. The purpose of the present study was to analyze the relationship between vitamin D and food allergy in infants and children.

We present the following article in accordance with the Narrative Review reporting checklist (available at https:// dx.doi.org/10.21037/tp-21-396).

\section{Methods}

We searched the PubMed database to identify studies on the relationship between vitamin D and food allergy published 
between January 2003 and August 2021. The search terms included vitamin $\mathrm{D} / 25$-hydroxyvitamin $\mathrm{D}$, food allergy/ atopic disease/allergic disease, child/children and infant/ infants.

The selection criteria were as follows: (I) studies associated with the theme; and (II) original articles, reviews, systematic reviews, and meta-analyses. The studies were limited to those in English only.

\section{Vitamin D metabolism}

Vitamin D is a cyclopentane polyhydrophenanthrene compound. The 7-dehydrocholesterol in the skin is converted into vitamin D3 by photochemical action and thermochemical action. Another important source for the body to absorb vitamin $\mathrm{D}$ is through the digestive tract, and possibly through passive diffusion and cholesterol transporters (1). Vitamin D binds to vitamin D binding protein (DBP) to form the vitamin D-DBP complex and is transported into the bloodstream via chylomicron. Vitamin D-DBP has no biological activity in vivo. The vitamin $\mathrm{D}$-DBP conjugate is metabolized by the liver into 25-hydroxyvitamin D (25-OHD) within a few hours. With the help of $1 \alpha$-hydroxylase (CYP27B1), 25-OHD is converted into calcitriol (1,25-OHD) in the kidney; 1,25 $\mathrm{OHD}$ then enters the cell and quickly transfers into the nucleus, where it binds to vitamin $\mathrm{D}$ receptors (VDR) and other components and creates biological responses.

\section{VDR and binding protein}

VDR is a nucleophilic protein composed of 427 amino acid residues, which is a member of the steroid hormone/ thyroid hormone receptor family. The VDR gene has 6 functional regions from the $\mathrm{N}$-terminal to C-terminal, AE. $\mathrm{A}$ and $\mathrm{B}$ are the transcriptional activation regulatory regions, and the $\mathrm{C}$ region is the DNA-binding region, which mainly participates in the binding of vitamin D response elements. VDR exists in many cells (including B cells, T cells, dendritic cells and macrophages) and tissues outside the kidney, and it is closely related to vitamin D function. DBP is a multifunctional glycoprotein. It is a single peptide chain composed of 458 amino acids. It can be expressed in multiple tissues of the human body. DBP is highly polymorphic and is mainly synthesized by the liver. The DBP gene polymorphism will affect the expression level of the DBP protein and the affinity of VDR. There is increasing evidence that the combination of 25-OHD and
DBP may reduce the bioavailability of vitamin D (2).

\section{Role of vitamin D in pregnant woman and offspring}

During pregnancy, levels of vitamin D, calcium, and related hormones can change. In a previously published study, it was reported that offspring did not show obvious abnormal blood calcium or abnormal manifestations of the skeletal system at the beginning of life if their mothers had severe vitamin D deficiency (VDD), 1,25-OHD deficiency, or corresponding receptor deficiency during pregnancy (3). In a follow-up study of 380 pregnant women and their children, maternal VDD in late pregnancy was not found to be associated with any allergic reaction in the first year after birth (4).

However, it is worth noting that if there is VDD after birth, the risk of hypocalcemia and rickets is greatly increased, and the deficiency may lead to metabolic disorders of the extraosseous system. There are many epidemiological surveys on vitamin D levels in infants and young children nationwide; VDD is more common in newborns (5).

\section{Food allergy}

The prevalence of food allergy has increased in recent decades and is now recognized as a substantial public health burden in relatively developed countries. Children with food allergy can show esophagitis, enterocolitis and rectal colitis in acute and subacute stages. Some children may be accompanied by parenteral symptoms, such as respiratory symptoms, atopic dermatitis and so on. The infants or children with food allergy are required to avoid the culprit allergen. However, that is likely to lead to nutritional disorders include poor growth, micronutrient deficiencies and feeding difficulties (6). The micronutrients that have received many attentions have been vitamin D, possibly due to cow's milk allergy being one of the most prevalent food allergies in early childhood. Therefore, it is more necessary to study the relationship between food allergy and vitamin D.

\section{Clinical research on vitamin $D$ and allergic diseases}

Studies suggest that vitamin D seems to maintain the integrity of the mucosal barrier, preventing the intestinal immune system from being exposed to food allergens, and reducing the permeability of the intestinal mucosa to 
limit allergens (7). The barrier function of the intestinal mucosa is essential for the prevention of food allergies. The lack of vitamin D leads to more serious intestinal damage. The damaged intestinal mucosa will allow low doses of sensitive food proteins to penetrate into the immune system, which will stimulate B lymphocytes to produce more immunoglobulin $\mathrm{E}$ ( $\mathrm{IgE})$, then increases the Th2type allergic immune response, engendering disorders in innate epithelial defense (8). This results in impaired intestinal barrier function or vitamin D-mediated changes in the composition of the gastrointestinal microbiota. In a previously published study, Lack proposed the hypothesis of dual allergen exposure, and suggested that skin exposure to food protein through a disrupted skin barrier may lead to allergic sensitization and food allergy. That is, food allergy occurs through skin exposure in early life. The increase in skin permeability, such as eczema, is more likely to induce food allergy (9).

Due to the way vitamin $\mathrm{D}$ is produced, many studies on different latitudes, seasons, and light intensities are being carried out. A US study combined National Hospital Ambulatory Medical Care Survey data for ED visits to non-institutional hospitals from 1993 to 2005 of about 17.3 million people who were diagnosed with acute allergy. The study found that there were 5.5 visits per 1,000 visits in the northeast and 4.9 visits per 1,000 in the south, with a much stronger correlation between latitudinal gradients and food-induced anaphylaxis than other causes (10). Another large study collected and analyzed the data of 7,376 children in the USA from two authorized institutions. They found that food allergy was more common in babies born in autumn compared with any other season (11).

There are various studies on food allergy in people with VDD. In a national health and nutrition survey of 3,136 children in the USA, the relationship between 17 allergens and VDD was evaluated. Compared with children with normal vitamin D levels, children with VDD are more likely to be allergic to peanut, ragweed and oak (12). This research doesn't point out why children with VDD are prone to allergies to these allergens. There are few relevant studies now. Segovia-Ortí et al.'s study shows Vitamin D status is associated with sensitization to dust mite, and cat and dog dander (13). Some articles believe that there is no correlation between VDD and various allergens (14). In a large-scale cohort study in Australia, the researchers compared the data of 5,276 children, and found that infants with VDD were over twice as likely to suffer from multiple food allergies compared with ordinary infants. VDD children's probability of food allergy is 6 times than that of ordinary children, and they are more likely to have peanut and egg allergies (15). On the contrary, if children with food allergy do not avoid allergic foods, their risk of VDD and zinc deficiency will also be greatly increased, even if these children are taking vitamin D and mineral supplements (16).

However, part of studies showed negative results. In a recently published meta-analysis, no significant association was reported between vitamin D and IgE-mediated food allergy (17). In a case cohort study of 1,074 infants, there was no evidence that VDD occurs in infants in the first 6 months is a risk factor for food allergy at 1 year of age (18). Many prospective studies have also shown the same results, and they indicated that 25-OHD is not related to food allergy $(19,20)$.

In addition, some studies have shown that higher levels of 25-OHD are associated with an increase in the incidence of allergic diseases (21-23). In a Japanese randomized, controlled study of 164 children with eczema, vitamin D (800 IU/d) and placebo supplements were individually supplied for 6 weeks, and it was found that there was no significant difference in the severity of eczema between the two groups after 3 months. However, vitamin D supplementation was found to increase the risk of food allergy in the future (24). In Finland, 975 infants participated in a randomized, controlled trial, supplemented with 400 or 1,200 IU vitamin D every day starting from 2 weeks of age. The infants were followed up to determine the occurrence of allergic diseases at 12 months of age. The results showed that high-dose vitamin $\mathrm{D}$ supplementation did not prevent infants from developing allergic diseases or asthma within 1 year of birth. In contrast, infants who were randomly assigned to receive higher doses vitamin $\mathrm{D}$ had an increased risk of milk allergy, as did infants with high cord blood vitamin D levels (25). Although these randomized, controlled trials did not provide data on vitamin $\mathrm{D}$ levels at the time of evaluation, they still indicate that high concentrations of vitamin D may have side-effects. Therefore, some scholars have proposed that there may be a nonlinear relationship between the change of vitamin D levels and allergic diseases.

There is still no consensus on the recommendations of infant feeding, and many researches mention the role of vitamin D. For example, in a case-control study of 200 children in Kuwait, the protective effect of exclusive breastfeeding on atopic diseases was more obvious during 4-6 months of exclusive breastfeeding. Prolonging breastfeeding time will increase the risk of allergy and may 
cause VDD in infants (26). This view was supported by Koplin et al., who found that breastfed infants who delayed eating eggs were twice as likely to develop an egg allergy by the age of 1 year. Introducing egg into the diet at 46 months of age could prevent egg allergy. This mechanism may be related to the fact that abundant vitamin $\mathrm{D}$ in eggs can reduce the risk of allergy (27). In addition, studies have shown that appropriate vitamin D levels may improve gastrointestinal symptoms in children with food allergy (28). Therefore, vitamin D supplementation seems to provide a basis for hygiene theory (29).

More and more studies have shown that children with food allergy who avoid allergens have the health problem of low weight, which appears to be linked to the number of foods excluded. The contradiction is particularly prominent in infants with milk protein or egg protein allergy under the age of 1 year, because milk and eggs are one of the most nutritious foods in this period. If the nutritional substitutes are not appropriate, the gains will outweigh the losses (30). Koplin's view inspired us that avoiding milk or eggs may aggravate VDD, resulting in an increased risk of food allergy. The new view is that nutritionists should be more cautious about dietary recommendations for children with food allergies (30), and increase consideration of the role of vitamin D.

Vitamin D has seasonal characteristics and is affected by indoor and outdoor activities, diet, skin and digestive tract diseases, genetic susceptibility, multiple metabolic pathways, and multiple metabolic steps. Food allergy may have inaccurate definitions in the clinical setting, and allergen types are diverse, making relevant research more complicated. Up to now few high-quality randomized, controlled studies on Vitamin D and food allergy have been conducted.

\section{Vitamin D participates in the immune regulation of allergic diseases}

Vitamin D can help regulate the development of the innate and adaptive immune system through a number of ways. Current research indicates that Th1 and Th2 subset ratio and functional imbalance are the main immune pathogeneses of allergy. Vitamin D interferes with Th1 cytokine secretion by inhibiting the proliferation of $\mathrm{T}$ cells. The effect of vitamin D on Th2 cells is still unclear. Vitamin D can induce Tregs to secrete interleukin (IL)-10, thereby reducing the activity of Th2 cells (31). Vitamin D can also reduce the production of IL-12 and increase the differentiation of Th2 cells (32). As well as this, vitamin D can also stabilize the adaptive immune system by inhibiting Th1/Th17 cells and inducing Tregs.

Studies on the relationship between serum IgE levels and vitamin D remain unclear, and it is generally believed that vitamin $\mathrm{D}$ can affect the production of IgE. Vitamin D can increase the production of $\mathrm{IgE}$ by shifting the balance of Th1/Th2 to Th2 cells. It can also reduce the secretion of $\mathrm{IgE}$ by blocking the proliferation of B lymphocytes and inducing Tregs (32). IL-4 and IL-13 are the only known cytokines that can induce isotype $\operatorname{IgE}$ conversion, and IL-4 is also known to play an important role in $\mathrm{IgE}$ regulation. There is a significant interaction between $I L-4$ gene polymorphism (rs2243250) and VDD (33). Most studies indicate that 25-OHD levels are significantly negatively correlated with total $\mathrm{IgE}$ and eosinophil count (34), and increasingly more recent studies are finding that 25-OHD and IgE levels own relationship of nonlinear $(22,35)$.

Vitamin D has a strong antiproliferative effect on CD4+ $\mathrm{T}$ cells, and it can directly participate in the differentiation of dendritic cells. It can also inhibit the function of $\mathrm{T}$ lymphocytes by acting on antigen-presenting cells (36). The current consensus is that a reasonable vitamin D level is conducive to the tolerance of dendritic cells and increases the expression of CD31, which can shorten the interaction time between dendritic cells and naive $\mathrm{T}$ cells to inhibit immunogenic T cells (37). Vitamin D3 may reduce symptomatic food allergy by inhibiting CD69+ and CD4+ $\mathrm{T}$ cells, indicating that the reduction of CD69+ and CD4+ $\mathrm{T}$ cells can help reduce food allergy (38). It has also been suggested that vitamin D3 can inhibit the activation of mast cells to control allergic diarrhea (39).

Toll-like receptors (TLRs) can regulate immunemediated allergic reactions. Infants susceptible to atopic diseases have low expression levels of TLR2, TLR4, and TLR9. It's confirmed that exogenous 25-OHD in vitro recovered TLR-induced antimicrobial responses (40). In Poole et al.'s study, a significant correlation between vitamin $\mathrm{D}$ and TLR2 pathways was found, indicating that vitamin D may upregulate the TLR pathway (41).

Some studies have found that Tregs regulate the immune response by inhibiting the activation of Th2 cells and the production of $\operatorname{IgE}(42)$. Vitamin D can induce Tregs produced by IL-10 to express low levels of FoxP3+ Tregrelated transcription factors. Studies have found that the vitamin $\mathrm{D} 3$ level can be associated with the number of FoxP3 + Tregs in peripheral blood (43), and it has also been found that testing serum Treg values and 25-OHD levels 
can be used as reference indicators to diagnose cow's milk protein allergy in infants (44). In addition, the health status of people with VDD who take a vitamin D supplement $(140,000 \mathrm{IU})$ is significantly improved after 4 weeks, and this is related to the increase of Tregs (45).

At present, many studies have demonstrated that vitamin D makes a difference to food allergy, however, more indepth studies are needed. Future laboratory research should consider the immune regulation of vitamin $\mathrm{D}$ and the regulation of the $I L-4$ gene on $\mathrm{IgE}$ production, because these are the molecular bases that work together to influence the risk of food allergy. Serum total IgE, IgEmediated phenotype related gene, 1,25-OHD regulated genes, such as $H L A-D R B 1, S T A T 6$, and $I L-10$, warrant further study (32). Vitamin D could reduce food allergy by inhibit CD4, CD69, mast cells. And vitamin D could induce the production of Treg cells to affect immune system. A deeper understanding of these molecules will help develop more effective and safer treatment models. Current scientific research and clinical applications lack measurements of DBP levels, which is an important area for future research.

Furthermore, more large-scale, multicenter, prospective clinical trials need to be conducted to determine the best effective dose of vitamin D. For example, randomized, controlled trials of vitamin D supplementation after birth need to be conducted to confirm whether vitamin D plays a key role in the occurrence of food allergy in early life, and studies on infantile eczema and food allergies need to be developed. Allergic diseases are also apparent in later childhood, and long-term follow-up of the study cohort is also necessary. Large-scale observational studies and clinical trials can be replicated. The real mechanism of light intensity (including region, season, and indoor and outdoor activity time), diet, skin and digestive tract diseases, genetic susceptibility, and other effects on infants' food allergy is still confusing, therefore further analyses are warranted in future studies. Different types of food allergies have different genetic and clinical phenotypes. Future genomic research will also help clarify the potential role of vitamin $\mathrm{D}$ in the development and regulation of allergic diseases.

\section{Limitations}

The present study has some limitations. First, the study is based on the authors' own summary of the literature. Therefore, its publication bias could exist. Second, the study only covers the scientific research in the last 15 years, and only covers articles published in major journals in the field. Therefore, limitations affecting the outcomes might exist.

\section{Conclusions}

Vitamin D is mainly synthesized by the skin and ingested through the digestive tract, which is affected by many factors before it produces biological effects. Fetal vitamin D levels remain stable during the fetal period, even if the mother has VDD; however, if the newborn has low vitamin D levels, the probability of abnormal immune metabolism, including allergy, will increase. Early-stage skin care for babies may reduce the incidence of food allergy in infancy. Vitamin D may prevent the intestinal immune system from being exposed to allergens by maintaining the integrity of the mucosal barrier, thereby reducing the occurrence of food allergy. Completely avoiding allergens may increase VDD, then lead to poor growth of the children with food allergy. Many laboratory studies have indicated that vitamin $\mathrm{D}$ is involved in a variety of immune regulation mechanisms. Of these, IL-4 and Treg cells have demonstrated a high correlation with allergic diseases. In clinical and laboratory studies, the deep relationship between vitamin $\mathrm{D}$ and allergic diseases remains unclear, and a nonlinear relationship may exist, which warrants further study.

\section{Acknowledgments}

Funding: None.

\section{Footnote}

Reporting Checklist: The authors have completed the Narrative Review reporting checklist. Available at https:// dx.doi.org/10.21037/tp-21-396

Conflicts of Interest: Both authors have completed the ICMJE uniform disclosure form (available at https://dx.doi. org/10.21037/tp-21-396). The authors have no conflicts of interest to declare.

Ethical Statement: The authors are accountable for all aspects of the work in ensuring that questions related to the accuracy or integrity of any part of the work are appropriately investigated and resolved. 
Open Access Statement: This is an Open Access article distributed in accordance with the Creative Commons Attribution-NonCommercial-NoDerivs 4.0 International License (CC BY-NC-ND 4.0), which permits the noncommercial replication and distribution of the article with the strict proviso that no changes or edits are made and the original work is properly cited (including links to both the formal publication through the relevant DOI and the license). See: https://creativecommons.org/licenses/by-nc-nd/4.0/.

\section{References}

1. Reboul E, Goncalves A, Comera C, et al. Vitamin D intestinal absorption is not a simple passive diffusion: evidences for involvement of cholesterol transporters. Mol Nutr Food Res 2011;55:691-702.

2. Koplin JJ, Suaini NH, Vuillermin P, et al. Polymorphisms affecting vitamin D-binding protein modify the relationship between serum vitamin D (25OHD3) and food allergy. J Allergy Clin Immunol 2016;137:500-506.e4.

3. Kovacs CS. The role of vitamin D in pregnancy and lactation: insights from animal models and clinical studies. Annu Rev Nutr 2012;32:97-123.

4. Woon FC, Chin YS, Ismail IH, et al. Maternal vitamin D levels during late pregnancy and risk of allergic diseases and sensitization during the first year of life-a birth cohort study. Nutrients 2020;12:2418.

5. Yu X, Wang W, Wei $Z$, et al. Vitamin D status and related factors in newborns in Shanghai, China. Nutrients. 2014 Dec 4;6(12):5600-10.

6. Meyer R. Nutritional disorders resulting from food allergy in children. Pediatr Allergy Immunol 2018;29:689-704.

7. Wu J, Zhong Y, Shen $\mathrm{X}$, et al. Maternal and early-life vitamin $\mathrm{D}$ deficiency enhances allergic reaction in an ovalbumin-sensitized BALB/c mouse model. Food Nutr Res 2018.

8. Wollenberg A, Seba A, Antal AS. Immunological and molecular targets of atopic dermatitis treatment. Br J Dermatol 2014;170 Suppl 1:7-11.

9. Lack G. Epidemiologic risks for food allergy. J Allergy Clin Immunol 2008;121:1331-6.

10. Rudders SA, Espinola JA, Camargo CA Jr. Northsouth differences in US emergency department visits for acute allergic reactions. Ann Allergy Asthma Immunol 2010;104:413-6.

11. Keet CA, Matsui EC, Savage JH, et al. Potential mechanisms for the association between fall birth and food allergy. Allergy 2012;67:775-82.
12. Sharief S, Jariwala S, Kumar J, et al. Vitamin D levels and food and environmental allergies in the United States: results from the National Health and Nutrition Examination Survey 2005-2006. J Allergy Clin Immunol 2011;127:1195-202.

13. Segovia-Ortí R, Barceló Bennasar A, De Sotto-Esteban D, et al. Association between vitamin $\mathrm{D}$ status and allergen sensitization in pediatric subjects in the Balearic Islands. Pediatr Allergy Immunol 2021;32:1183-9.

14. Guo Y, Yu L, Deng YH, et al. Associations between serum 25-hydroxyvitamin D levels and allergic sensitization in early childhood. Allergol Immunopathol (Madr) 2020;48:84-9.

15. Allen KJ, Koplin JJ, Ponsonby AL, et al. Vitamin D insufficiency is associated with challenge-proven food allergy in infants. J Allergy Clin Immunol 2013;131:110916, 1116.e1-6.

16. Meyer R, De Koker C, Dziubak R, et al. A practical approach to vitamin and mineral supplementation in food allergic children. Clin Transl Allergy 2015;5:11.

17. Willits EK, Wang Z, Jin J, et al. Vitamin D and food allergies in children: a systematic review and meta-analysis. Allergy Asthma Proc 2017;38:21-8.

18. Molloy J, Koplin JJ, Allen KJ, et al. Vitamin D insufficiency in the first 6 months of infancy and challengeproven IgE-mediated food allergy at 1 year of age: a casecohort study. Allergy 2017;72:1222-31.

19. Ercan N, Bostanci İB, Ozmen S, et al. Is there an association between vitamin $\mathrm{D}$ levels and cow's milk protein allergy at infancy? Arch Argent Pediatr 2019;117:306-13.

20. Jones AP, Palmer D, Zhang G, et al. Cord blood 25-hydroxyvitamin D3 and allergic disease during infancy. Pediatrics 2012;130:e1128-35.

21. Hyppönen E, Berry DJ, Wjst M, et al. Serum 25-hydroxyvitamin D and $\operatorname{IgE}$ - a significant but nonlinear relationship. Allergy 2009;64:613-20.

22. Cairncross C, Grant C, Stonehouse W, et al. The relationship between vitamin $\mathrm{D}$ status and allergic diseases in New Zealand preschool children. Nutrients 2016;8:326.

23. Weisse K, Winkler S, Hirche F, et al. Maternal and newborn vitamin $\mathrm{D}$ status and its impact on food allergy development in the German LINA cohort study. Allergy 2013;68:220-8.

24. Norizoe C, Akiyama N, Segawa T, et al. Increased food allergy and vitamin D: randomized, double-blind, placebocontrolled trial. Pediatr Int 2014;56:6-12.

25. Rosendahl J, Pelkonen AS, Helve O, et al. High-dose 
vitamin D supplementation does not prevent allergic sensitization of infants. J Pediatr 2019;209:139-45.e1.

26. Alkazemi D, Albeajan M, Kubow S. Early infant feeding practices as possible risk factors for immunoglobulin E-mediated food allergies in Kuwait. Int J Pediatr 2018;2018:1701903.

27. Koplin JJ, Osborne NJ, Wake M, et al. Can early introduction of egg prevent egg allergy in infants? A population-based study. J Allergy Clin Immunol 2010;126:807-13.

28. Guo H, Zheng Y, Cai X, et al. Correlation between serum vitamin $\mathrm{D}$ status and immunological changes in children affected by gastrointestinal food allergy. Allergol Immunopathol (Madr) 2018;46:39-44.

29. Bloomfield SF, Rook GA, Scott EA, et al. Time to abandon the hygiene hypothesis: new perspectives on allergic disease, the human microbiome, infectious disease prevention and the role of targeted hygiene. Perspect Public Health 2016;136:213-24.

30. Skypala IJ, McKenzie R. Nutritional issues in food allergy. Clin Rev Allergy Immunol 2019;57:166-78.

31. Xystrakis E, Kusumakar S, Boswell S, et al. Reversing the defective induction of IL-10-secreting regulatory T cells in glucocorticoid-resistant asthma patients. J Clin Invest 2006;116:146-55.

32. Lee SJ, Kang BH, Choi BS. Vitamin D serum levels in children with allergic and vasomotor rhinitis. Korean J Pediatr 2015;58:325-9.

33. Liu X, Wang G, Hong X, et al. Gene-vitamin D interactions on food sensitization: a prospective birth cohort study. Allergy 2011;66:1442-8.

34. Brehm JM, Celedón JC, Soto-Quiros ME, et al. Serum vitamin D levels and markers of severity of childhood asthma in Costa Rica. Am J Respir Crit Care Med 2009;179:765-71.

35. Rothers J, Wright AL, Stern DA, et al. Cord blood 25-hydroxyvitamin D levels are associated with

Cite this article as: $\mathrm{Di} \mathrm{T}$, Chen L. A narrative review of vitamin $\mathrm{D}$ and food allergy in infants and children. Transl Pediatr 2021;10(10):2614-2620. doi: 10.21037/tp-21-396 aeroallergen sensitization in children from Tucson, Arizona. J Allergy Clin Immunol 2011;128:1093-9.e1-5.

36. Mahon BD, Wittke A, Weaver V, et al. The targets of vitamin $\mathrm{D}$ depend on the differentiation and activation status of CD4 positive T cells. J Cell Biochem 2003;89:922-32.

37. Cantorna MT, Rogers CJ, Arora J. Aligning the paradoxical role of vitamin $\mathrm{D}$ in gastrointestinal immunity. Trends Endocrinol Metab 2019;30:459-66.

38. Zaim E, Ashino S, Osaka T, et al. Effect of cholecalciferol in food allergy mouse model is associated with decrease of CD69+ CD4+ T cells. J Nutr Sci Vitaminol (Tokyo) 2019;65:113-22.

39. Liu ZQ, Li XX, Qiu SQ, et al. Vitamin D contributes to mast cell stabilization. Allergy 2017;72:1184-92.

40. Walker VP, Zhang X, Rastegar I, et al. Cord blood vitamin D status impacts innate immune responses. J Clin Endocrinol Metab. 2011 Jun;96(6):1835-43.

41. Poole A, Song Y, O'Sullivan M, et al. Children with nut allergies have impaired gene expression of Tolllike receptors pathway. Pediatr Allergy Immunol 2020;31:671-7.

42. Palomares O, Yaman G, Azkur AK, et al. Role of Treg in immune regulation of allergic diseases. Eur J Immunol 2010;40:1232-40.

43. Chambers ES, Nanzer AM, Richards DF, et al. Serum 25-dihydroxyvitamin D levels correlate with CD4(+) Foxp3(+) T-cell numbers in moderate/severe asthma. J Allergy Clin Immunol 2012;130:542-4.

44. Perezabad L, López-Abente J, Alonso-Lebrero E, et al. The establishment of cow's milk protein allergy in infants is related with a deficit of regulatory T cells (Treg) and vitamin D. Pediatr Res 2017;81:722-30.

45. Prietl B, Pilz S, Wolf M, et al. Vitamin D supplementation and regulatory $\mathrm{T}$ cells in apparently healthy subjects: vitamin $\mathrm{D}$ treatment for autoimmune diseases? Isr Med Assoc J 2010;12:136-9. 